Jahrbuch Schweiz - Dritte Welt 1991

\title{
Wieso sollte die Schweiz den Institutionen von Bretton Woods beitreten?
}

Hans Ith

\section{(2) OpenEdition \\ 12 Journals}

Electronic version

URL: http://journals.openedition.org/sjep/1214

DOI: $10.4000 /$ sjep. 1214

ISSN: 1663-9677

Publisher

Institut de hautes études internationales et du développement

\section{Printed version}

Date of publication: 1 janvier 1991

Number of pages: 207-209

ISSN: 1660-5926

\section{Electronic reference}

Hans Ith, «Wieso sollte die Schweiz den Institutionen von Bretton Woods beitreten?»,

Schweizerisches Jahrbuch für Entwicklungspolitik [Online], 10 | 1991, Online erschienen am: 13 April

2013, abgerufen am 08 September 2020. URL : http://journals.openedition.org/sjep/1214 ; DOI :

https://doi.org/10.4000/sjep.1214 


\title{
Wieso sollte die Schweiz den Institutionen von Bretton Woods beitreten?
}

\author{
Hans Ith
}

Der Grundsatzentscheid des Bundesrates, den Institutionen von Bretton Woods (Internationaler Wăhrungsfonds; Weltbank und ihre Tochterinstitute) beizutreten, wurde im August 1982 gefăllt, im gleichen Monat, in dem die Schuldenkrise ausbrach. Es war indessen nicht die internationale Verschuldung, welche unsere politischen Instanzen davon abhielt, den Beitritt zu vollziehen, sondern die negative UNO-Abstimmung. Zur Verzögerung beigetragen hat aber auch die kritische Einstellung entwicklungspolitischer Kreise gegenüber dem Internationalen Wăhrungsfonds.

Seither haben sich die internationalen Interdependenzen - im positiven wie im negativen Sinn - weiter verstärkt und zu einer kaum für möglich gehaltenen Entspannung in den Beziehungen zwischen den beiden Supermăchten geführt. Damit einher ging eine Aufwertung der multilateralen Gremien. Auf aussenpolitischer Ebene bedeutet dies für die Schweiz, dass ihre "Nischenpolitik der guten Dienste" an Bedeutung verliert. Zudem wird ihr Abseitsstehen bei wirtschaftsund wăhrungspolitischen Entscheidungen international immer weniger verstanden.

Wenn die Schweiz in diesen Zeiten des Umbruchs ihre eigene Identităt bewahren will, so wird sie sich nicht darauf beschrănken können, einen Platz im integrierten Europa zu finden, sondern sie wird auch ihre weltweiten Beziehungen neu regeln müssen. Diese Aussage gilt ganz besonders im Verhăltnis zu den Institutionen von Bretton Woods.

Was den Internationalen Währungsfonds (IWF) betrift, so hat er Aufgaben zu erfüllen, die für die wirtschaftlich stark vom Ausland abhängige Schweiz von erheblicher Bedeutung sind. Zum einen ist er beauftragt, die währungsmässigen 
Voraussetzungen für ein gutes Funktionieren der Weltwirtschaft zu schaffen, zum andern übernimmt er wichtige Funktionen bei der Lósung des Schuldenproblems. Die Weltbank ihrerseits ertült neben ihrer angestammten Tâtigkeit in der Entwicklungshilfe zunehmend auch Aufgaben im Umweltschutzbereich.

Die Schweiz hat zwar auch bisher das Wirken dieser Institutionen mit namhaften Beitrăgen unterstützt, ihre Mőglichkeiten der Mitsprache und der Mitgestaltung waren jedoch beschrănkt.

Diese Ausgangslage veranlasste den Bundesrat, anfangs Juni 1990 die Bewerbungsschreiben für die Mitgliedschaft beim Internationalen Wahrungtonds und bei der Weltbank einzureichen. Seither hat das aus 13 Exekutivdirektoren bestehende Mitgliedschaftskomitee des IMF dreimal getagt, ohne sich aber auf eine Quote für unser Land einigen zu können. Dennoch darf davon ausgegangen werden, dass die Schweiz einen Kapitalanteil erhălt, der ihren Vorstellungen entspricht.

Dies würde es dem Bundesrat ermöglichen, in einer Botschaft an die eidg. Răte den Beitritt der Schweiz zu den Institutionen von Bretton Woods zu beantragen. Da diese Vorlage dem fakultativen Referendum unterstünde, stellt sich die Frage, ob das Referendum ergriffen und die Vorlage vor dem Volk gegebenenfalls Gnade finden würde. Einiges legt den Schluss nahe, dass die referendumspolitische Hürde genommen werden könnte.

Entwicklungspolitische und kirchliche Kreise befürworten seit lăngerer Zeit einen Beitritt unter der Voraussetzung, dass sich die Schweiz im IWF auf eine Politik verpflichtet, die nicht im Widerspruch zum schweizerischen Entwicklungshilfegesetz steht. Auch die Sozialdemokratische Partei hat sich am Parteitag 1990 dieser Haltung angeschlossen. Ebenfalls in diese Richtung bewegte sich die Erklărung von Bern, auch wenn ihre Bedingungen restriktiver gehalten sind.

Darin widerspiegelt sich die grundsătzliche Anerkennung des Prinzips der Konditionalităt, d.h. der Einsicht, dass die Entwicklungslănder ihre vielfăltigen Probleme nur lösen können, wenn sie wirtschafts- und wăhrungspolitische Vorkehren zur Gesundung ihrer Volkswirtschaften ergreifen. Diese Massnahmen sind sozialvertrăglich auszugestalten, denn nur so kann vermieden werden, dass das Wirtschaftspotential eines Landes langfristig Schaden nimmt. Wenn die Schweiz Mitglied des IWF wird, verbessern sich die Möglichkeiten, auf den in Gang befindlichen Prozess der Neugestaltung der Konditionalităt Einfluss zu nehmen und unsere diesbezüglich reichen Erfahrungen einzubringen.

Opposition gegen einen Beitritt zu den Institutionen von Bretton Woods haben bisher nur die Aktion für eine unabhängige und neutrale Schweiz (AUNS) sowie die Aktion Finanzplatz Schweiz-Dritte Welt angemeldet. Für die in bürgerlichen Kreisen verankerte AUNS dürtte es jedoch schwierig sein, die Vertreter der Wirtschaft mehrheitlich von ihrer Haltung zu überzeugen. Denn es darf nicht ausser acht gelassen werden, dass schweizerische Export-Unternehmungen ein nicht unerhebliches Interesse daran haben, an Projektausschreibungen der Weltbank wie Konkurrenten aus Mitgliedslăndern teilnehmen zu kőnnen.

Diese Gleichstellung konnte bisher erreicht werden, weil die Schweiz ihren Kapitalmarkt der Weltbank für ihre Kreditaufnahme uneingeschrănkt zur Vertü- 
gung stelte und die Eidgenossenschaft Entwicklungsprojekte in Form von Kofinanzierungen über diese Institution abwickelte. Wegen der Liberalisienung der internationalen Finanzmårkte verliert der Finanzplatz Schweiz als Argument für die Gleichbehandlung zunehmend an Zugkraft. Hinzu kommt, dass auch Mitgliedstaaten der Weltbank damit begonnen haben, die bisherige "schweizerische Spezialităt" der Kofinanzienung zu betreiben.

Über kurz oder lang könnten somit jene Krăfte wieder Auftrieb erhalten, denen die schweizerische Gleichstellung immer ein Dom im Auge war. Dies ganz besonders deshalb, weil es der schweizerischen Wirtschaft bisher immer gelang, einen überproportional hohen Anteil der Ausschreibungen an sich zu ziehen.

Zusammenfassend darf festgehalten werden, dass die Schweiz gute Gründe für einen Beitritt zu den Institutionen von Bretton Woods hat, auch wenn die Motive unterschiedlicher Art sind. Sie zeigen, dass sich wirtschaftliche und entwicklungspolitische sowie aussenpolitische und wăhrungspolitische Gesichtspunkte durchaus vereinbaren lassen. 